\title{
Laparoscopic Nephroureterectomy: Oncologic Outcomes
}

\author{
Andre Berger and Amr Fergany*
}

\begin{abstract}
Section of Laparoscopic and Robotic Surgery, Glickman Urological Institute, Cleveland Clinic Foundation, Cleveland, Ohio 44195, USA
\end{abstract}

\begin{abstract}
Purpose of Review: Laparoscopic radical nephroureterectomy (LNU) is being increasingly performed at several centers across the world. This review analyzes the published perioperative and oncologic outcomes of this procedure.

Recent Findings: Laparoscopic radical nephroureterectomy (LNU) for upper tract TCC is performed pure laparoscopically (LNU) or hand-assisted (HALNU). The most debated issues for oncologic outcomes are management of the distal ureter and lymphadenectomy. LNU appears to have superior perioperative outcomes when compared to open surgery. Although long-term outcomes after LNU are limited, intermediate term oncologic outcomes are comparable to open nephroureterectomy (ONU), the reference standard.

Summary: Intermediate term oncologic outcomes for LNU compare well with ONU. Initial long-term oncologic outcomes are encouraging. Prospective randomized comparison between LNU and open surgery is needed to define the role of these modalities in the current context.
\end{abstract}

Keywords: Nephroureterectomy, laparoscopic, oncologic outcomes.

\section{INTRODUCTION}

Upper tract TCC is relatively uncommon accounting for only $5 \%$ of all urothelial tumors [1]. It usually occurs between 6th and 7th decades of life. Classical management consists of open radical nephroureterectomy (ONU), which usually requires one large or two separate abdominal incisions. Since LNU was first reported by the Washington University Group in 1991 [2], the benefits of this procedure regarding perioperative morbidity, cosmesis and convalescence have been established [3-5]. Mainly, there are 2 laparoscopic approaches: pure laparoscopic nephroureterectomy (LNU) and hand-assisted nephroureterectomy (HALNU). Despite the perioperative advantages, some oncological issues remain unclear, mainly management of the distal ureter and the role of lymphadenectomy.

\section{MANAGEMENT OF DISTAL URETER}

The management of the distal ureter is still controversial. In 1952, McDonald et al. first reported an endoscopic method to handle the distal ureter [6]. In the laparoscopic era, many attempts have been made to avoid the open approach to the distal ureter, which is still commonly used. Matin et al. (2004) compared the outcomes (median follow-up 23 months) using the two different techniques of en bloc excision of bladder cuff: 36 patients underwent needlescopic percutaneous transvesical cystoscopic secured detachment [7] and 12 underwent laparoscopic extravesical stapling. The stapling technique was associated with a decreased overall survival, decreased recurrence free survival and higher positive surgical margin rate. Kurzer et al. (2006) evaluated 49 patients on a mean follow-up of 10.6 months) and reported

*Address correspondence to this author at the Glickman Urological Institute/A100, Cleveland Clinic Foundation, Cleveland, Ohio 44195, USA; Tel: 216-444-0414; Fax: 216-445-2267; E-mail: fergana@ccf.org their results after cystoscopic circumferential excision of the distal ureter without primary closure of the bladder cuff with simultaneous ureteral ligation during HALNU [8]. No cases of local pelvic or peritoneal recurrences were reported. Vardi et al. (2006) reported a new technique to manage the distal ureter [9]. They purposed an en bloc excision of the bladder cuff and justavesical ureter during HALNU using a flexible cystoscope and a $5 \mathrm{~F}$ electrode without repositioning the patient. Mean follow up was 31 months (range 5-44) and none of the 6 patients presented with local recurrence. Recently, Nanigian et al. (2006) reported using robotic assistance in an attempt to decrease the technical challenge of excision of distal ureter in 11 patients [10]. As part of the procedure, they filled the bladder with a saline solution before opening it and aspirated all the fluid to avoid dissemination of cancer cells. In addition to the disadvantage of increased cost, the 6 months follow-up is not enough to evaluate local recurrence.

Since most studies do not show any difference between different methods of handling the distal ureter, the best option is to follow individual surgeon's preference as long as the fundamental oncological concepts are preserved: having a complete resection of the distal ureter with bladder cuff and avoiding tumor spillage.

\section{LYMPHADENECTOMY}

Recently, the importance of extended lymph node dissection for bladder cancer regarding staging and prognosis has been established. Given the histological similarity between bladder cancer and upper tract TCC, lymphadenectomy should also be important for the management of upper tract TCC. Kondo et al. (2007) evaluated 169 patients that underwent open nephroureterectomy divided in 3 different groups: complete lymphadenectomy, incomplete lymphadenectomy and no lymphadenectomy [11]. Extended lymphadenectomy improved survival in patients with pT3 stage or higher. On multivariate analysis, complete lymphadenectomy, $\mathrm{T}$ stage 
and grade were significant prognostic factors for cancerspecific survival. Brausi et al. (2007) reported retroperitoneal lymph node dissection and $\mathrm{T}$ stage as the only independent significant prognostic factors on overall survival [12]. Busby et al. (2006) found no difference between ONU and LNU concerning number of lymph nodes retrieved, median number of positive nodes retrieved and median density of positive nodes, showing that lymphadenectomy can be performed in the laparoscopic approach as adequately as in open approach [13].

\section{ONCOLOGICAL OUTCOMES AFTER LNU}

Laparoscopic nephroureterectomy is performed utilizing the same surgical principles as laparoscopic radical nephrectomy. A transperitoneal (Fig. 1) or retroperitoneal approach (Fig. 2) can be used. Most surgeons are familiar with the transperitoneal approach, which has the advantage of allowing dissection of the ureter all the way to the bladder. This is essential if endoscopic management of the distal ureter (as previously described) is planned. Surgeons familiar with the retroperitoneal approach to radical nephrectomy can perform the renal part of the operation retroperitoneally, although access to the distal ureter is difficult with this approach. This is best suited to cases where the distal ureter will be managed through an open approach. In either case the ureter is not divided and left in continuity. A clip placed on the ureter will minimize the risk of tumor seeding resulting from manipulation of the kidney. In cases of ureteric tumors, careful attention to wide dissection of the ureter is essential to avoid a positive margin or entry into the ureter with tumor spillage.

Long-term follow-up after ONU is well documented in some large series. Charbit et al. (1991) reported the first big follow up series with upper tract TCC in 108 patients [14]. Survival rates after 5 and 10 years were $67 \%$ and $65 \%$, respectively. Hall et al. (1998) reviewed 252 patients after ONU (median follow-up 64 months). Recurrence occurred in $67(27 \%)$ patients and urothelial recurrences represented $69 \%$ of total [15]. Median time to recurrence was 12 months.

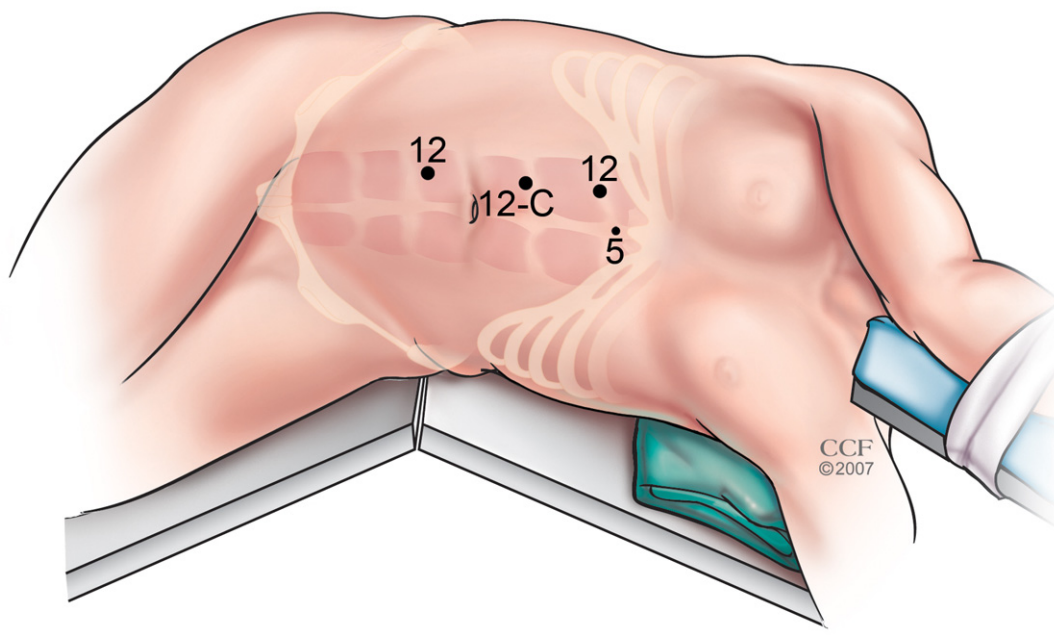

Fig. (1). Port placement during right transperitoneal radical nephroureterectomy. (A) primary $12 \mathrm{~mm}$ port is placed in the right border of the rectus muscle 3 fingerbreadths above the umbilicus. (B) $12 \mathrm{~mm}$ port is placed in the same line $3 \mathrm{~cm}$ above the first one (C) $12 \mathrm{~mm}$ port is placed in the same line 3 fingerbreadths below the umbilicus. (D) $5 \mathrm{~mm}$ is placed in the midline at the sternal angle (and used to retract the liver).

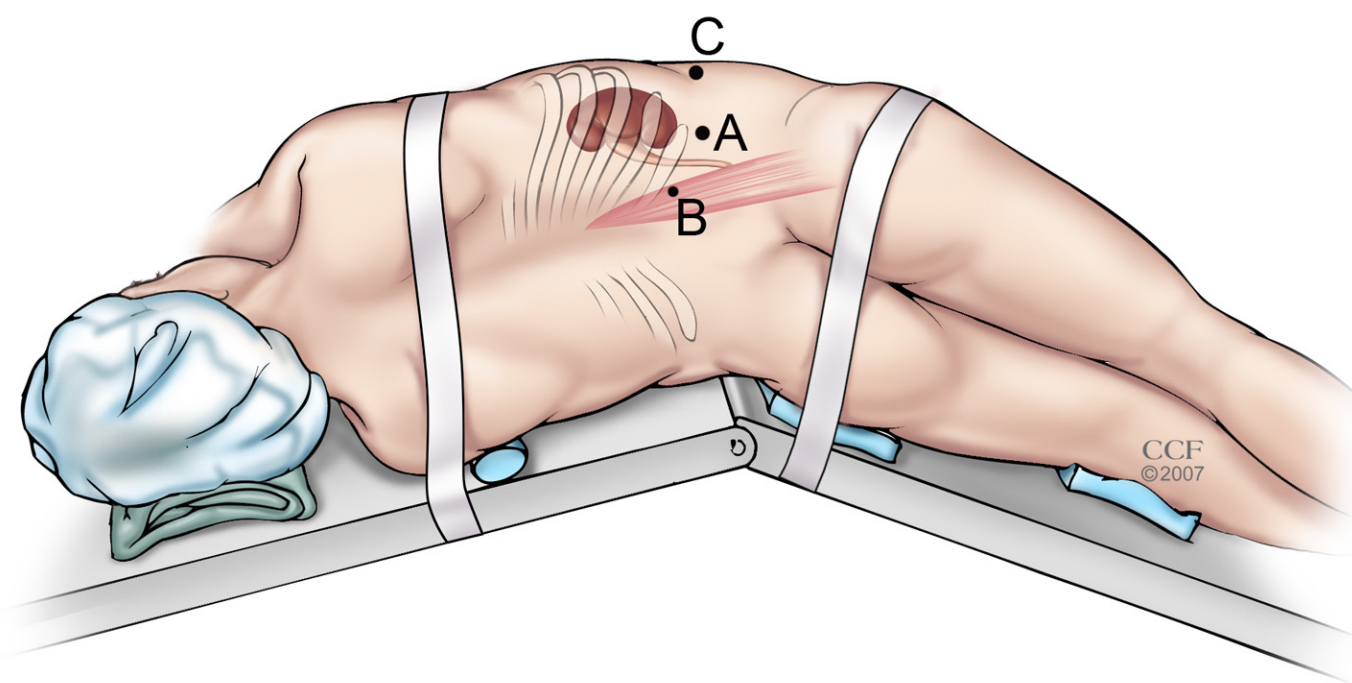

Fig. (2). Port placement during right retroperitoneal radical nephroureterectomy. (A) primary 10-mm port is placed at the tip of 12th rib. (B) $10-/ 12-\mathrm{mm}$ port is placed at junction of lateral border of the erector spinae muscle with lower edge of 12th rib. (C) 10-/12-mm port is placed three fingerbreadths cephalad to iliac crest, between mid and anterior axillary lines. 
Actuarial 5-year cancer-specific survival rates by primary tumor stage were $100 \%$ for $\mathrm{Ta} / \mathrm{Cis}, 92 \%$ for $\mathrm{T} 1,73 \%$ for $\mathrm{T} 2$, and $41 \%$ for T3. Median survival for pT4 patients was 6 months. On multivariate analysis, tumor stage was a significant predictor for recurrence, whereas patient age and stage were significant predictors for survival. In contrast, a multicenter study by Ozsahin et al. (1999) evaluated 126 patients with upper tract TCC (median follow-up 39 months) and reported poor oncological outcomes of ONU [16]. In a median period of 9 months, $66 \%$ of the patients recurred. The 5 and 10 -year overall survivals were $29 \%$ and $19 \%$, respectively. Multivariate analysis revealed that independent prognostic factors influencing outcome were $\mathrm{T}$ staging, positive surgical margin and tumor in the ureter. Lower survival rates in this study may be explained by high proportions of high grade $(76 \%)$, non-organ confined disease $(59 \%)$, and positive surgical margin $(26 \%)$.

Long term follow-up studies after LNU are still sparse. El Fettouh et al. (2002) reported the results of 116 patients who underwent LNU on a multicenter basis with a median follow-up of 25 months [17]. Positive margins were identified in $4.5 \%$ of patients, local recurrence in $1.7 \%$, bladder recurrence in $24 \%$ and mean time to recurrence was 13.9 months. Distant metastasis rate was 9\%; mean time to metastasis was 13 months. Two-year cancer-specific survival was $87 \%$. According to $\mathrm{T}$ stage, 2 -year cancer specific survival was $89 \%$ for $\mathrm{pT} 1,86 \%$ for $\mathrm{pT} 2,77 \%$ for $\mathrm{pT} 3$ and $0 \%$ for pT4. Muntener et al. (2007) reported the outcomes of 39 patients after LNU (median follow-up 74 months). Five-year cancer specific survival was $68 \%$. Tumor stage was the only factor related to cancer death and ureteral tumor was the only factor associated with recurrence [18].

Cohorts comparing perioperative and short/intermediate oncological outcomes between ONU and LNU have been published. Bariol et al. (2004) evaluated 25 patients who underwent LNU and 42 who underwent ONU for TCC in a median follow-up of 101 and 96 months, respectively [19]. Local and bladder recurrence rates were $28 \%$ (7 patients) for LNU and $42 \%$ (15 patients) for ONU while more ureteral tumors were described in ONU. One and 5-year metastasesfree survivals were $80 \%$ and $72 \%$ for LNU and $87 \%$ and
$82 \%$ for ONU, while no statistical difference between the two surgical treatments was found. Roupret et al. (2006) compared 20 patients who underwent LNU (median followup 68.5 months) to 26 who underwent ONU (median followup 78 months). Recurrence occurred in $20 \%$ of cases of LNU and $53 \%$ of ONU [20]. Median time to recurrence was 15 and 18 months, respectively. Five-year cancer-specific survival was $90 \%$ and $61 \%$ and 5 -year recurrence-free survival was $71 \%$ and $51 \%$, respectively. Okegawa et al. (2006) compared $25 \mathrm{LNU}$ (mean follow-up 24 months) and $23 \mathrm{ONU}$ (mean follow-up 29 months). In LNU and ONU groups, recurrence rates were $20 \%$ and $17 \%$ and mean time to recurrence were 9.5 and 23.4 months [21]. Distant metastasis rate was $8 \%$ for LNUX and $13 \%$ for ONUX. Two-year cancerspecific survival was $91 \%$ for LNU and $89 \%$ for ONU. No significant difference was detected in recurrence-free survival and cancer-specific survival. Manabe et al. (2007) evaluated 58 patients after LNU (mean follow-up 13.6 months) and 166 after ONU (mean follow-up 28 months). Bladder recurrence was reported in $33 \%$ of patients after LNU and in 38\% after ONU [22]. Distant metastases were reported in $17 \%$ and $20 \%$ of the patients, respectively. The 2 -year recurrence- free survivals were $76 \%$ and $82 \%$. No difference was found in cancer-specific survival.

Some recent series report results after hand-assisted LNU (HALNU), but oncologic outcomes are limited. Wolf et al. (2005) evaluated 54 patients who underwent HALNU with median follow up of 25 months [23]. Urothelial recurrences occurred in $66 \%$ patients. History of bladder tumors was associated with urothelial recurrence. Non-urothelial recurrences were found in $25 \%$ of the patients at a mean 10.4 months follow-up. Age and grade correlated with nonurothelial recurrence. The 2 and 3-year- cancer-specific survival were $86 \%$ and $80 \%$, respectively. Organ- confined disease and non organ-confined disease were associated with a 3 -year survival of $100 \%$ and $36 \%$ respectively. High-grade disease correlated with poorer 3-year cancer-specific survival. Chung et al. (2007) also described comparable recurrence free, 3-year cancer-specific and overall survivals in 39 patients after HALNU (median follow-up 48 months) and 41 patients after ONU (median follow-up 62 months) [24].

Table 1. LNU Series and Comparative Studies

\begin{tabular}{|c|c|c|c|c|c|c|c|c|c|}
\hline & $\begin{array}{l}\text { Patients } \\
\text { (n) }\end{array}$ & $\begin{array}{l}\text { Median } \\
\text { Follow-Up } \\
\quad(\mathrm{mo})\end{array}$ & $\begin{array}{c}\text { Recurrence } \\
(\%)\end{array}$ & $\begin{array}{c}\text { Local } \\
\text { Recurrence } \\
(\%)\end{array}$ & $\begin{array}{l}\text { Bladder } \\
\text { Recur- } \\
\text { rence }(\%)\end{array}$ & $\begin{array}{c}\text { Distant } \\
\text { Metas- } \\
\text { tasis (\%) }\end{array}$ & $\begin{array}{c}\text { Overall Sur- } \\
\text { vival (\%) }\end{array}$ & $\begin{array}{c}\text { Cancer- } \\
\text { Specific } \\
\text { Survival (\%) }\end{array}$ & $\begin{array}{l}\text { Risk Factor } \\
\text { Associated to } \\
\text { Survival (\%) }\end{array}$ \\
\hline $\begin{array}{l}\text { El Fettouh } \\
(2002)[17]\end{array}$ & 116 & 25 & Not stated & Not stated & 24 & 9 & Not stated & 87 ( 2 year) & Not stated \\
\hline \multicolumn{10}{|c|}{ LNU X Open Surgery } \\
\hline $\begin{array}{c}\text { Bariol } \\
\text { (2004) [19] }\end{array}$ & $\begin{array}{c}58 \\
26 / 22\end{array}$ & $101 / 96$ & Not stated & $8 / 15$ & $28 / 42$ & $28 / 18$ & $56 / 9$ & $72 / 82$ (5 year) & Not stated \\
\hline $\begin{array}{l}\text { Roupret } \\
(2006)[20]\end{array}$ & $\begin{array}{c}46 \\
20 / 26\end{array}$ & $68 / 78$ & $\begin{array}{l}19 \text { (urothe- } \\
\text { lial) }\end{array}$ & Not stated & Not stated & $10 / 35$ & Not stated & $90 / 61$ (5 year) & $\begin{array}{l}\text { Tumor stage } \\
\text { and grade }\end{array}$ \\
\hline
\end{tabular}


The propensity for dissemination of high grade TCC is well known. An important concern with laparoscopic approach is port site metastasis. Seven cases have been published so far. No surgical bag was used in six cases and the surgical bag was torn during retrieval of the specimen in one case [24].

Intermediate oncological outcomes after LNU are similar to ONU. Series combining long follow up and large number of patients are lacking. Finally, to confirm these previous encouraging findings, prospective randomized trials are still needed.

\section{CONCLUSION}

LNU is now being performed in many centers worldwide. Many series have demonstrated technical feasibility and safety. Although large numbers of 5-year oncologic data are not yet available in the LNU literature, reports indicate that intermediate and long term oncological outcomes are similar to ORC. Carefully designed prospective randomized trials comparing LNU and ONU are necessary to define the role of these modalities in the current and future management of upper tract TCC.

\section{REFERENCES}

[1] Tawfiek ER, Bagley DH. Upper-tract transitional cell carcinoma. Urology 1997; 50: 321-9.

[2] Clayman RV, Kavoussi LR, Figenshau RS. Laparoscopic nephroureterectomy: initial case report. J Laparoendosc Surg 1991; 1: 343-9.

[3] Gill IS, Sung GT, Hobart MG, et al. Laparoscopic radical nephroureterectomy for upper tract transitional cell carcinoma: the Cleveland Clinic experience. J Urol 2000; 164: 1513-22.

[4] Shalhav AL, Dunn MD, Portis AJ, et al. Laparoscopic nephroureterectomy for upper tract transitional cell cancer: the Washington University experience. J Urol 2000; 163(4): 1100-4.

[5] Tsujihata M, Nonomura N, Tsujimura A, et al. Laparoscopic nephroureterectomy for upper tract transitional cell carcinoma: comparison of laparoscopic and open surgery. Eur Urol 2006; 49(2): 332-6.

[6] Mc Donald HP, Upchurch WE, Sturdevant CE. Nephroureterectomy: a new technique. J Urol 1952; 67: 804-9.

[7] Matin S, Gill IS. Recurrence and survival following laparoscopic radical nephroureterectomy with various forms of bladder cuff control. J Urol 2004; 173: 395-400.

[8] Kurzer E, Leveillee R, Bird V. Combining hand-assisted laparoscopic nephroureterectomy with cystoscopic circumferential excision of the distal ureter without primary closure of the bladder cuffis it safe? J Urol 2006; 173: 63-8.

[9] Vardi I, Stern J, Gozalez C, Kimm S, Nadler R. Novel technique for manegement of distal ureter and en bloc resection of bladder cuff during hand-assisted laparoscopic nephroureterectomy. Urology 2006; 67: 89-92.

[10] Nanigian D, Smith W, Ellison L. Robot-assisted laparoscopic nephroureterectomy. J Endourol 2006 20: 463-5.

[11] Kondo T, Nakazawa H, Ito F, Hashimoto Y, Toma H, Tanabe K. Impact of the extent of regional lymphadenectomy on the survival of patients with urothelial carcinoma of the upper urinary tract. J Urol 2007; 178(4 Pt 1): 1212-7

[12] Brausi M, Gavioli M, Verrini G, Peracchia G, Viola M. Retroperitoneal lymph node dissection (RPLND) in conjunction with nephroureterectomy in the treatment of infiltrative transitional cell carcinoma (TCC) of upper urinary tract: impact on survival. Eur Urol 2007; 52: 114-8.

[13] Busby J, Brown G, Matin S. Efficacy of lymphadenectomy during laparoscopic radical nephroureterectomy: comparison to the open approach [abstract]. J Urol 2006; 175(Suppl. 4): 344

[14] Charbit L, Gendreau MC, Mee S, Cukier J. Tumors of the upper urinary tract: 10 years of experience. J Urol 1991; 146(5): 1243-6.

[15] Hall MC, Womack S, Sagalowsky AI, Carmody T, Erickstad MD, Roehrborn CG. Prognostic factors, recurrence, and survival in transitional cell carcinoma of the upper urinary tract: a 30 -year experience in 252 patients. Urology 1998; 52(4): 594-601.

[16] Ozsahin M, Zouhair A, Villà S, et al. Prognostic factors in urothelial renal pelvis and ureter tumours: a multicentre Rare Cancer Network study. Eur J Cancer 1999; 35(5): 738-43.

[17] El Fettouh HA, Rassweiler JJ, Schulze M, et al. Laparoscopic nephroureterectomy: results of an international multicenter study. Eur Urol 2002; 42: 447-55.

[18] Muntener M, Schaeffer EM, Romero FR, et al. Long term oncologic outcome after laparoscopic radical nephroureterectomy for upper tract transitional cell carcinoma. Eur Urol 2007; 51(6): 16394.

[19] Bariol SV, Stewart GD, McNeill SA, Tolley DA. Oncological control following laparoscopic nephroureterectomy: 7-year outcome. J Urol 2004; 172: 1805-8.

[20] Rouprêt M, Hupertan V, Sanderson KM, et al. Oncologic control after open or laparoscopic nephroureterectomy for upper tract: a single center experience. Urology 2006; 69: 256-61.

[21] Okegawa T, Odagane A, Ide H, Horie S, Nutahara K, Higashihara E. Oncological outcomes of retroperitoneoscopic nephroureterectomy for upper urinary tract transitional cell carcinoma. Int J Urol 2006; 13: 493-7.

[22] Manabe D, Saika T, Ebara S, et al. Comparative study of oncologic outcomes of laparoscopic nephroureterectomy and standard nephroureterectomy for upper tract transitional cell carcinoma. Urology 2007; 69: 457-61.

[23] Wolf JS Jr, Dash A, Hollenbeck BK, Johnston WK 3rd, Madii R, Montgomery JS. Intermediate followup of hand assisted laparoscopic nephroureterectomy fo $\mathrm{r}$ urothelial carcinoma: factors associated with outcomes. J Urol 2005; 173(4): 1102-07

[24] Chung SD, Chueh SC, Lai MK, et al. Long-term outcome of handassisted laparoscopic radical nephroureterectomy for upper-tract urothelial carcinoma: comparison with open surgery. J Endourol 2007; 21(6): 595-9. 